\title{
Developing Social Skills of Summer Campers with Autism Spectrum Disorder: A Case Study of Camps on TRACKS Implementation in an Inclusive Day-Camp Setting
}

\author{
Kimberly Maich \\ Brock University \\ Carmen L. Hall \\ Fanshawe College of Applied Arts and Technology \\ Tricia Marie van Rhijn \\ University of Guelph \\ Laurie Quinlan \\ City of London
}

\begin{abstract}
This research provides preliminary results of an exploratory case study conducted of the Camps on TRACKS program in an inclusive, municipal day-camp program in southwestern Ontario, Canada. Positive changes are demonstrated in the social skills of nine day campers with an autism spectrum disorder (ASD) who participated in the program. In this model of social inclusion, all campers were taught skills to interact with peers with exceptionalities through a peer-mediated model. Social skills change was measured using direct observation and counsellor questionnaires. Primary findings included an overall increase in social skills in campers with an ASD, and an inverse relationship between adult and peer interactions. Camps on TRACKS is a promising model for supporting the social skills development of campers with an ASD in inclusive settings.
\end{abstract}

The scene is all too familiar in camp settings: a group of children playing soccer, while a camper with exceptionalities sits on the sidelines with a support counsellor. This camper with special needs occasionally joins in, but only with the support counsellor alongside. He or she is physically present with his or her fellow campers, but because physical 
proximity with neurotypical peers is often not enough to significantly improve social skills (Laushey \& Heflin, 2000; McConnell, 2002), this camper is not fully benefitting from social opportunities that make camp such a positive environment. His or her peers may not pass the ball to the camper because they are intimidated by the counsellor, or run past the child because the child is holding hands with an adult. Such traditional one-onone support may limit opportunities for inclusion, as the adult may act as a barrier to interactions with same-age peers (Giangreco, Edelman, Luiselli, \& MacFarland, 1997).

Social skills are an important foundation for all children and are inextricably intertwined with peer relationships in all social settings, including school, community, and summer camp. The social skills domain is one of the five foundational domains of child development and includes interactions with others, including making friends, helping skills, and empathy (Best Start Expert Panel on Early Learning, 2007). Children with autism spectrum disorder (ASD) and other exceptionalities may not observe and acquire the social skills like their neurotypical peers in everyday social situations, and often need to be directly and intensively taught these skills (Myles, Simpson, Ormsbee, \& Erikson, 1993). A peer-mediated approach is seen as a positive intervention to counteract this difficulty, as it involves teaching peers how to engage with and teach children with social challenges, thus creating positive social opportunities and social skill development (Sperry, Neitzel, \& Engelhardt-Wells, 2010). Peer-mediated interventions are one of the most well-researched, effective methods for increasing social interaction skills in children with ASD (McConnell, 2002), but researchers have just begun to explore barriers and successes in recreation environments, especially in fully inclusive summer camps where the focus continues to be on relationship development and physical activity (Brookman et al., 2003). In one such study, Spencer-Cavaliere and Watkinson (2010) specifically examined perceptions of inclusion by children with disabilities in physically active settings. The children with disabilities reported that inclusion occurred when peers invited or accepted their entrance to play situations. This entrance to play allowed them to feel included, being treated as legitimate participants despite their disability, and to self-identify as having friends.

The development of social skills, specifically in children with ASD, has been studied widely in clinical and school-based settings (Kashinath, 2012). This research helped to inform the development of Camps on TRACKS, a locally developed program guide created by a multidisciplinary team in southwestern Ontario, Canada, to teach peermediated social skills within a day-camp setting (Hall, Quinlan, Machado, Maich, \& Faragher, 2011). Developed from five behavioural strategies suggested for neurotypical peers in a peer-mediated approach (Thiemann, 2006), TRACKS is a simple acronym representing: try again (persistence), right thing (correcting), assist (prompting), congratulate (reinforcement), keep trying (persistence), and show (modeling). Table 1 provides a summary of its implementation. 


\section{Table 1}

\section{Description of Implementation Steps to Camps on TRACKS}

\begin{tabular}{ll}
\hline Number \& Title & Description \\
\hline Step 1: Introduction to TRACKS & $\begin{array}{l}\text { Introductions were conducted and activities were taught on } \\
\text { the first day of each weekly camp session to set up the } \\
\text { purpose of the Camps on TRACKS program, while setting } \\
\text { the tone for an inclusive environment. }\end{array}$ \\
A group reinforcement system was introduced to campers \\
and token attainment guidelines were explained. \\
Step 3: Camper Awareness & $\begin{array}{l}\text { Disability awareness activities were completed to } \\
\text { understand challenges that individuals with disabilities may } \\
\text { encounter, demonstrating that each person can overcome } \\
\text { barriers and achieve individual potential. }\end{array}$ \\
Step 4: Teaching TRACKS & $\begin{array}{l}\text { Peers were taught the TRACKS acronym, providing } \\
\text { practical tools for successful interactions with children with } \\
\text { diverse characteristics. }\end{array}$ \\
Step 5: Prompting Through Peers & $\begin{array}{l}\text { Camp counsellors were trained and provided ongoing } \\
\text { coaching on how to prompt peers to interact with the camper } \\
\text { with ASD and fade their proximity to promote socialization } \\
\text { and utilization of TRACKS strategies. }\end{array}$ \\
\hline
\end{tabular}

Hall, Quinlan, Machado, Maich, \& Faragher (2011)

Previous peer-mediated research has often relied on the training of small groups of peers in dyads or triads to enhance social skill development (Thiemann \& Goldstein, 2004). Although effective in increasing social skills for the identified children, the utility of this model in a natural setting is limited with increased camper enrolment and demands on camp staff. Families and service providers are increasingly seeking day camps for children with exceptionalities to focus on regular access to peers to develop social skills. As these needs increase, camp models that systematically teach social skills with peers, such as a peer-mediated approach in inclusive settings, are also needed.

Research studying the effectiveness of peer-mediated interventions has demonstrated that peer training can lead to positive outcomes for children with exceptionalities across multiple settings (Utley \& Mortweet, 1997; Zhang \& Wheeler, 2011). The studies examining the peer-mediated approach have spanned multiple purposes including tutoring, modeling, and social skill development. The majority of this research has been completed in inclusive, educational settings. In the most recent evidence-based practice report and a recent meta-analysis, peer-mediated strategies were found to be a robust and evidence-based practice for individuals with ASD (Bene, Banda, \& Brown, 2014; Wong et al., 2014). Utley and Mortweet (1997) have broken down peer-mediated interventions into six categories and termed interventions such as Camps on TRACKS, as peer initiation training. The goal of peer initiation training is to increase the social behaviours of children with disabilities; the intervention consists of training neurotypical peers how to initiate and respond to the target child (Utley \& Mortweet, 1997). 
Recently, more studies have investigated the use of peer-mediated approaches during leisure periods, such as at recess time and during physical education, as a way to include children with disabilities and increase social interactions with peers (Kamps et al., 2014; Klavina, 2011; Mason et al., 2014; McFadden, Kamps, \& Heitzman-Powell, 2014). Klavina (2011) found when peer-mediated strategies were used to include students with severe and multiple disabilities in general physical education classes, students were as actively engaged as their peers and two out of three participants showed higher activity engagement with peers and received more instructions from peers than in the teacherdirected condition. Positive effects have also been found when peer-mediated strategies have been incorporated with other interventions, often called peer networks (McFadden et al., 2014). "A peer network includes a focus child with ASD and a small group of teachernominated typically developing peers in which adult instruction is combined with peer mediation and is provided in integrated settings" (McFadden et al., 2014, p. 1700). Two studies demonstrated increases in social communication acts with the implementation of peer networks at recess, which included social skill lessons and/or teacher initiated reminders at the beginning of activities, reinforcement, and peer and child prompting (Mason et al., 2014; McFadden et al., 2014). In another study, Kamps and colleagues (2014) found that after a structured instruction followed by free play, a peer-mediated strategy was effective in increasing total social communication acts for two out of three children with ASD when in a triad with two other peers during the free play.

Although the literature has strong support for utilizing peer-mediated strategies during unstructured times such as during recess or free play, implementing this beyond the schools and into the community in summer camp settings is still in its infancy. Based on parental reports of the need for an inclusive setting over the summer months, Brookman and colleagues (2003) proposed a model for an inclusive summer camp to support the social development of children with autism. The model included recruitment and training of aides, creating individualized social goals for each camper, running contextually appropriate interventions, and communicating with families. In particular, aides were taught to facilitate peer interactions with the child with autism in natural settings. This exploratory study found that the model benefitted social skills development for children with autism with a range of functioning levels, benefitted camp counsellors and neurotypical peers, and was easy and efficient to implement.

Schleien, Mustonen, and Rynders (1995) examined the social interactions of children with autism and their peers who are typically developing by creating a cooperative monthly art class. The intervention consisted of activities and instructions that were co-operative rather than individualistic and focused on completing projects together. Peers were given an introduction session that provided strategies on interacting and working co-operatively with an individual with autism, and dyads were assigned and encouraged for the class. Results demonstrated that peers who were typically developing increased their rates of initiation toward individuals with autism from baseline, although children with autism did not increase rates of reciprocation or initiations toward these peers who were typically developing.

In a summer robotics day camp, adolescents with ASD and their typically developing peers were paired and engaged in a robotics curriculum (Kaboski et al., 2014). A pre-post assessment demonstrated increases in robotics knowledge and 
decreases in self-reported social anxiety across the verbal adolescents with ASD. No changes in social skills were seen in the study nor were they specifically targeted in the intervention.

In what appears to be the only peer-mediated intervention in a summer camp setting to date, Corbett and colleagues (2014) trained peers who were typically developing on various behavioural techniques for three days prior to a two-week theatre camp. Peer training was then followed by online videos that modeled the appropriate interactions with individuals with ASD throughout the two-week camp. Throughout this time period, individuals with ASD demonstrated increases in social cognition, facial recognition, and social awareness. Increased time was spent with familiar peers; however, these gains did not generalize to novel peers.

Overall, the goals of this present project were three-fold (see Figure 1). First, this pilot study aimed to increase the social skills of campers with ASD by implementing a systematic method of peer training within a fully inclusive setting. Second, the program aimed to increase the quantity of social interactions with peers for campers with ASD while decreasing interactions with adults by fading adult proximity and prompting peers. Third, the Camps on TRACKS program sought to increase the quality of social interactions with peers for campers with ASD.

\section{Methods}

In order to describe the elements of the Camps on TRACKS program, a logic model was developed as a tool or "the basis for a convincing story of the program's expected performance" (John \& Gretchen, 1999, p. 66). See Figure 1 for the details of its objectives, strategies, and activities, including the overall program goal of building authentic peer relationships in a social setting.

\section{Participants}

Following ethics approval from the research ethics board at the second author's college setting, nine day campers (seven males and two females aged 5-10 years with a parent-reported diagnosis of ASD) participated in this study, held in one mid-sized city in southwestern Ontario, Canada. All participants had a functional communication method, defined as verbal language, a fluent use of the Picture Exchange Communication System (PECS), or another type of augmented and alternative communication (AAC). Parents who registered their child in one of two primary inclusion sites in the municipal, city-run day camps, and whose child met the above criteria, were invited to participate at the time of registration. Subsequently, written, informed consent was obtained from the parent, guardian, or caregiver of each participant who was recruited through this initial contact.

Chosen participants - like all day campers - attended one to six (non-consecutive) weeks of day camp. In this study, four participants attended for only one week, three participants attended for two weeks, and two campers attended day camp for five or more weeks. See Table 2 for an overview of the ages, genders, communication styles, and diagnoses of each participant. 
Figure 1. Program logic model for Camps on TRACKS.

\begin{tabular}{|c|c|c|c|}
\hline $\begin{array}{l}\text { Target } \\
\text { group: }\end{array}$ & \multicolumn{3}{|c|}{$\begin{array}{l}\text { Summer day campers diagnosed with an Autism Spectrum } \\
\text { Disorder. }\end{array}$} \\
\hline Goal: & \multicolumn{3}{|c|}{ Building authentic peer relationships in a social setting. } \\
\hline Longer-term & \multicolumn{3}{|c|}{ Developing social skills through peer-to-participant interactions. } \\
\hline $\begin{array}{l}\text { Shorter-term } \\
\text { outcome } \\
\text { objectives: }\end{array}$ & $\begin{array}{l}\text { Increase social } \\
\text { skills of campers } \\
\text { with ASD. }\end{array}$ & $\begin{array}{l}\text { Increase quantity } \\
\text { of social } \\
\text { interaction } \\
\text { between typically } \\
\text { developing peers } \\
\text { and campers with } \\
\text { ASD. }\end{array}$ & $\begin{array}{l}\text { Increase quality of } \\
\text { social interaction } \\
\text { between typically } \\
\text { developing peers } \\
\text { and campers with } \\
\text { ASD. }\end{array}$ \\
\hline $\begin{array}{l}\text { Strategies or } \\
\text { components: }\end{array}$ & $\begin{array}{l}\text { Daily interactions } \\
\text { with typically } \\
\text { developing } \\
\text { campers. }\end{array}$ & $\begin{array}{l}\text { Implementation of } \\
\text { peer-mediated } \\
\text { program by camp } \\
\text { counsellors. }\end{array}$ & $\begin{array}{l}\text { Teaching positive } \\
\text { behavioural skills } \\
\text { to all campers with } \\
\text { ASD. }\end{array}$ \\
\hline $\begin{array}{l}\text { Program } \\
\text { activities: }\end{array}$ & $\begin{array}{l}\text { - Reinforcement } \\
\text { activities } \\
\text { - Opportunities for } \\
\text { social connection } \\
\text { with typically } \\
\text { developing peers. } \\
\text { - Ongoing support } \\
\text { from on-site } \\
\text { camp } \\
\text { counsellors. } \\
\text { - As-needed } \\
\text { support from on- } \\
\text { site inclusion } \\
\text { counsellors }\end{array}$ & $\begin{array}{l}\text { - Training (prior to } \\
\text { implementation) } \\
\text { - Resources- } \\
\text { program } \\
\text { documentation } \\
\text { - Consultation with } \\
\text { on-site inclusion } \\
\text { counsellors } \\
\text { - As-needed } \\
\text { coaching from } \\
\text { program } \\
\text { consultant } \\
\text { - Reinforcement } \\
\text { system }\end{array}$ & $\begin{array}{l}\text { - Disability } \\
\text { awareness } \\
\text { activities } \\
\text { - Skill } \\
\text { development } \\
\text { instruction } \\
\text { (TRACKS) } \\
\text { - Reinforcement } \\
\text { system }\end{array}$ \\
\hline
\end{tabular}


Table 2

\section{Characteristics of Summer Camper Participants in Camps on TRACKS}

\begin{tabular}{crcll}
\hline Site & Age & Gender & Diagnosis & Communication Method \\
\hline A & 10 & M & Autism spectrum & PECS \\
A & 8 & M & Autism spectrum & Functional verbal speech \\
A & 9 & F & DD \& PDD-NOS & Functional verbal speech \\
A & 9 & M & DD \& autism spectrum & PECS; very limited speech \\
A & 9 & M & Asperger's disorder & Functional verbal speech \\
A & 9 & F & DD \& autism & PECS \\
B & 10 & M & DD \& PDD-NOS & Limited speech; picture symbols \\
B & 5 & M & Autism spectrum & Functional verbal speech \\
B & 8 & M & DD \& autism spectrum & Functional speech \\
\hline
\end{tabular}

DD, Developmental disorder; PDD-NOS, Pervasive developmental disorder-not otherwise specified; PECS, Picture exchange communication system.

\section{Setting}

Two of the fifteen municipal day-camp sites that implemented the Camps on TRACKS program were selected to participate at research sites because of their relative sizes as larger centres, as well as their designation as the primary inclusion sites with their municipality. Each camp week was run from 9:00 a.m. to 4:00 p.m., Monday to Friday. Campers registered for one-week periods; however, many peers and identified campers returned and attended for multiple consecutive or non-consecutive weeks.

Throughout their week of day camp, each participant was in a group of same-age peers of approximately 12 other day campers who were typically developing. Each of these small groups was led by one main counsellor. Inclusion counsellors, in addition, were also present and supported children with exceptionalities - including participants in this study - on an as-needed basis. At each site, there were four to five of these small groups, with a total of approximately 50 campers per week, per research site.

\section{Staff Training}

In the two months before camp began, over 130 day-camp staff members who specialized in inclusion across the municipality were trained in Camps on TRACKS, including a consultant to support the camp sites in implementing the program, and a data collector trained in applied behavior analysis. In the month prior, all of the camp counsellors at the selected research sites were subsequently trained, provided with all the program materials, and participated in collaborative planning in order to implement Camps on TRACKS each week. Throughout the summer the consultant also provided ongoing coaching on-site to ensure the correct implementation of the intervention. 
Prior to the commencement of data collection in July, the data collector hired for this project was trained in specific data collection procedures. Training in data collection was implemented using videotape review, and continued until inter-observer agreement in tracking social conversations reached $80 \%$. No inter-observer agreement procedures were completed throughout the remainder of the study.

\section{Implementation of the Camps on TRACKS Program}

The purpose of Camps on TRACKS is to provide opportunities for meaningful social interactions between campers of all abilities. The program logic model for Camps on TRACKS is presented in Figure 1. This model demonstrates that the goal of the program is for children with ASD to build authentic peer relationships by providing opportunities for these children to develop their social skills through peer interactions. Full details of the program are available in a program guide (Hall et al., 2011). Five steps for Camps on TRACKS were implemented each week when day campers attended day camp (see Table 2 ). These five steps were documented in five separate booklets that camp counsellors could take with them to assist in each phase of the program. The booklets included games, suggested scripts, and debriefing documents. Each step was completed with the entire same-age camper group (i.e., peers who are typically developing and camper with ASD). Some components were carried out in the small same-age groups, while others were implemented in the large, centre-wide group.

To encourage peer interactions and the use of TRACKS-based skills, camp counsellors were trained to prompt through peers, rather than always directly assisting campers struggling with social skills, and a token reward-based group reinforcement system was implemented at each site. To encourage consistency in its implementation, all camp staff at both sites attended the same training event, received on-site coaching support from the same program coordinator, and utilized the same printed materials as reference tools.

\section{Research Design-An Exploratory Case Study}

In order to examine changes in social skills for the participants with ASD, two approaches to data collection were utilized. First, single-subject observational data of the children with ASD were collected each week during the day camp in an AB design. Direct observation of all nine participants occurred in three 15-minute intervals, three times daily across all five days of the camping week. Observations took place in varied camp activities across the daytime schedule of camp (e.g., structure activities, informal games, free time, etc.; see Gast [2010] and Isaac \& Michael [1997]). This was completed for one week per participant with ASD in July or August, using a data collection sheet derived from English, Shafer, Goldstein, and Kaczmarek's (1997) Buddy Skills Program. Data collection was aligned with the weekly camp structure: Baseline data were collected on Mondays, and intervention data was recorded from Tuesdays to Fridays. Observational data were coded by tracking all peer-to-peer and peer-to-counsellor interactions, from the initiation of the exchange (e.g., by a typically developing peer or TDC), throughout the direction and length of turns in each exchange (e.g., adult [A] to participant $[\mathrm{S}]$ and back to A), noting any prompting and non-verbal interactions. See 
Figure 2 for a visual examples of elements of English et al.'s (1997) tracking social interactions data collection sheet including all utilized codes.

Figure 2. Elements from English et al.'s (1997) Tracking Social Interactions Data Collection Sheet

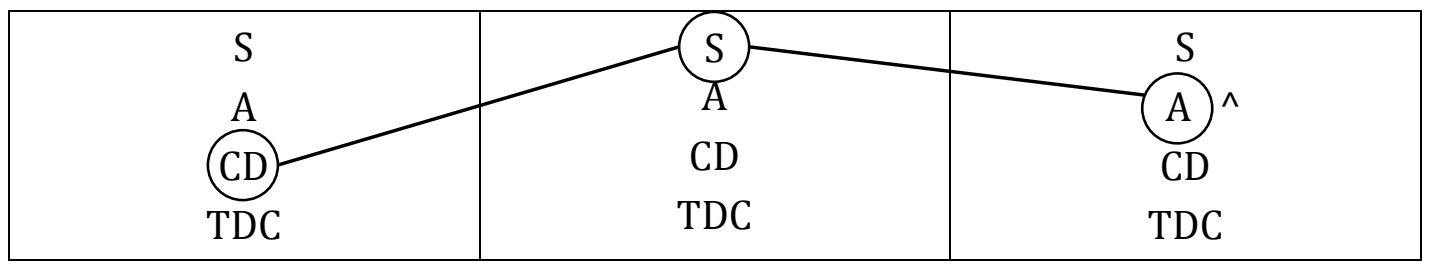

$S=$ Participant; $A=$ Adult; $C D=$ Child with Disability; TDC=Typically Developing Child. ${ }^{\wedge} T D C$ to $S$ to $A$ is an example of 1 unit of interaction with 3 conversational turns initiated by the TDC. "P" would be added for a prompt; "NV" would be added for a non-verbal interaction. Adapted from English et al. (1997).

Second, pre-post test data were collected from the camp counsellors. Each Monday and Friday, camp counsellors who had the most interaction with the child responded to a questionnaire rating perceived social skills change in the children with ASD (Isaac \& Michael, 1997). This was completed utilizing the internally stable and reliable 49-item, 3category Autism Social Skills Profile, which utilizes a four-point rating scale (Bellini, 2006; Bellini \& Hopf, 2007).

\section{Results}

Notable findings are evident related to the Camps on TRACKS program in these three areas: (a) increases in social skills in campers with ASD as a group, (b) moderate changes in total social interactions of four day-camper participants, and (c) a notable inverse relationship between interactions with adult camp counsellors, versus peer-topeer interactions.

\section{Social Skills Questionnaires}

Overall, camp counsellor ratings of social skills in the children with ASD increased from pre- to post-intervention. The summed score was calculated on the Autism Social Skills Profile (Bellini, 2006) across all nine participants. Scores across participants increased from a mean of 112.4 to 124.9 at pre-intervention and post-intervention, respectively. Refer to Figure 3 for a visual summary. 
Figure 3. Mean Sum Score on the Autism Social Skills Profile Across Participants, Pre- and Post-Camps on TRACKS Intervention.

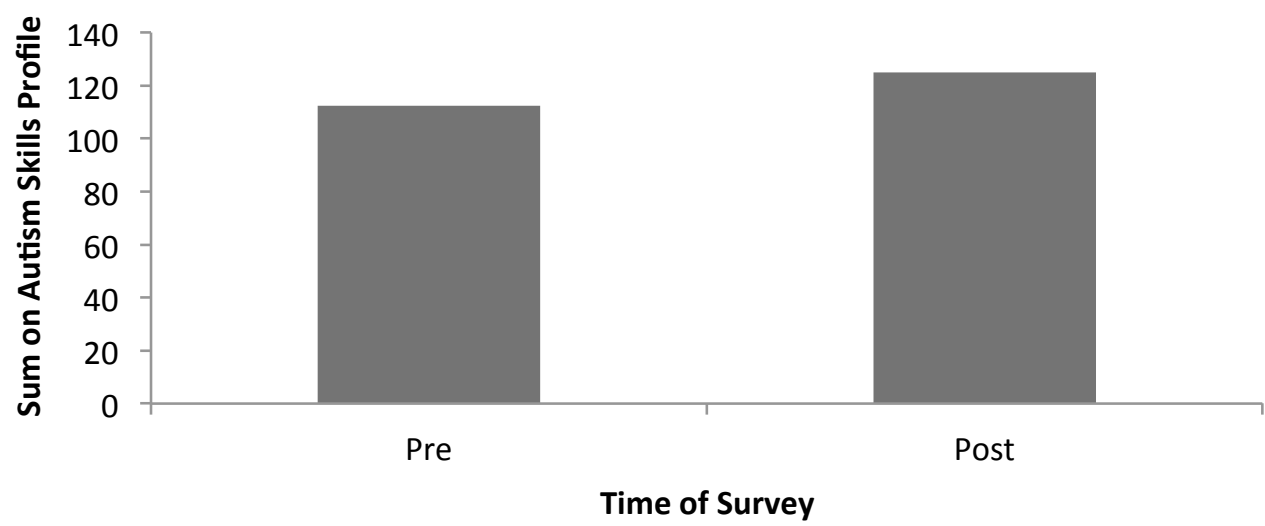

\section{Change in Social Interactions}

Observational data were analyzed for the total number of social interactions initiated by each child with ASD. Four of the nine participants demonstrated an overall increase in their number of social interactions when calculating the Improvement Rate Difference (IRD). The IRD is calculated as a percentage of difference in behaviour from baseline to intervention, and is typically utilized in single-participant research with multiple contextual variables affecting the study, such as those in diverse, inclusive environments (Kazdin, 1978; Parker, Vannest, \& Brown, 2009) such as Camps on TRACKS. In these four participants, the IRD demonstrated a low to moderate increase in social initiations with a range between $19 \%$ and $70 \%$. There was no difference in social skill improvement between those campers who attended one week and those who attended multiple weeks throughout the summer. This may be partially due to having different peers at camp each week as well.

Changes were often more noticeable in the quality of interactions, and not always the number of interactions. Campers were often found interacting with peers in more socially appropriate manners such as reciprocally playing in the group game rather than talking about a special interest. In addition, those individuals who used PECS to communicate were often observed engaging in meaningful reciprocal interactions with peers using toys and eye gaze. These were significant interactions with peers but were not recorded due to the nature of the data recording method. One parent who observed the Camps on TRACKS program saw her non-verbal daughter playing a game with a group, while a peer grabbed her hand and ran with her to the next station, meeting the game's objective and avoiding the other team. The parent was emotional, noting that she had never seen her daughter participate in a group game with a peer before or have friends.

\section{Inversion of Interactions}

In examining the interactions between the campers with ASD and counsellors, a visual inversion occurred. Counsellor-to-participant interactions were found to occur at differing frequency levels compared to peer-to-participant interactions in the same 
observational period across participants. For example, when a high frequency of counsellor-to-participant interactions occurred, the peer-to-participant interactions were lower frequency. This inverted effect also occurred in the converse direction. See Figure 4 for an example of this effect with one camper participant. This trend supports the viewpoint that close, proximal adult support leaves fewer opportunities for peers to interact with children with an exceptionality (Giangreco et al., 1997).

Figure 4. The Inverse Relationship Between the Numbers of Interactions Initiated by Adults Versus Those Initiated by Typically Developing Campers for One Participant During Camps on TRACKS.

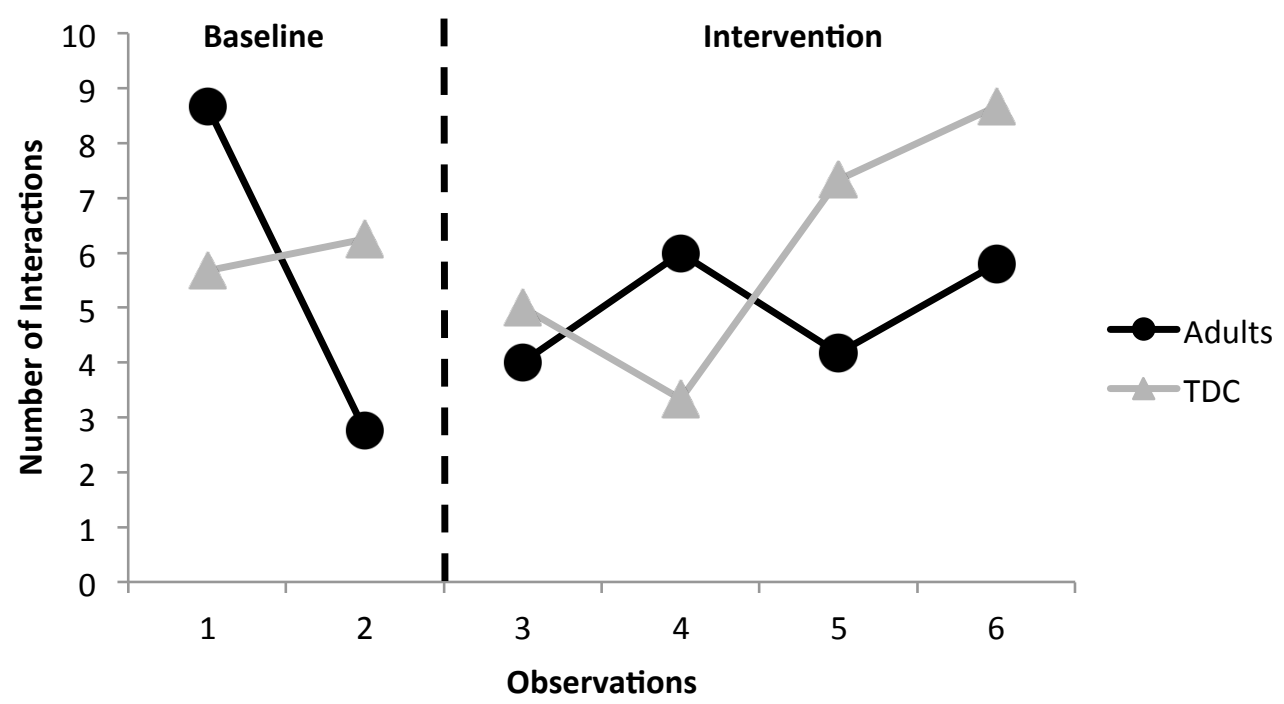

\section{Discussion}

Overall, results demonstrate initial support for the Camps on TRACKS program as a context for positive social skills development and for building authentic peer relationships in a social setting. An increase in the Autism Social Skill Profile captured subtle changes in social skills not necessarily evident in direct observation data related to the program's first short-term objective: increasing the social skills of campers with ASD. Increases in overall social interactions among four of nine campers in the singlesubject $\mathrm{AB}$ design also demonstrates initial support, but had increased variability due to rotating peers and activities in the natural setting across multiple sites. Similar to the results of an integrated art program, there was little stability in initiations across days, which may be a result of the different activities that were presented in each session (Schleien et al., 1995).

The inverse relationship between adult-to-participant versus peer-to-participant interactions is positive but perhaps unsurprising, given the program goals of Camps on TRACKS, which include a second short-term objective of increasing the quantity of 
social interaction between peers who are typically developing and peers with ASD. Throughout the program, camp counsellors were taught to decrease their proximity to the children with disabilities and to prompt peer interactions. As Giangreco and colleagues (1997) have shown, adult proximity can hinder social interactions with peers. Therefore, when counsellors were present and interacting, it appears that interactions with peers decreased. When their presence faded, peers interacted more with the participants. This demonstrates the substantial importance in training camp counsellors to fade physical proximity and approach campers with exceptionalities only when adult assistance is required.

Results of the Camps on TRACKS program demonstrate a promising practice that needs further investigation related to the third and final short-term objective: increasing the quality of social interaction between typically developing peers and peers with ASD. Anecdotal comments from parents enhanced the program's social validity; for example, "Everywhere I go, children are stopping and saying 'Hi," remarked the parent of a camper with ASD, continuing with, "He has so many camper friends." The overall inclusion and participation of campers with ASD was also captured through the use of the pre-post questionnaire completed by camp counsellors, demonstrating the overall positive effect of utilizing a peer-mediated approach to include children with exceptionalities, teaching peers how to successfully interact, and to promote overall acceptance and understanding. Finally, similar trends across participants demonstrated that the presence of adult interactions appeared to decrease peer interactions, thus demonstrating the need for increased use of peer-mediated strategies across settings for children with ASD.

Several aspects of the current study limit the results of this exploratory work and highlight the need for continued future research. Despite the use of quantitative measures, the small sample size limits generalizability; therefore, primarily qualitative findings are provided. In addition, the diverse range of campers with ASD, who had varying diagnoses and communication methods, made it difficult to compare social interactions across participants. Further limitations include the short intervention period due to the weekly camp structure and the lack of a control group that would compare social skills changes in the camping environment without this intervention.

More practically, camp staff members are in an exceptional position to encourage prompting through peers, but may initially find it challenging to implement this approach. Future studies should examine treatment fidelity across camp counsellors to ensure consistency of this approach. Practice and persistence are essential if staff members are going to be able remind themselves of opportunities to encourage peer participation, and subsequently to remember to fade physical proximity and approach campers with exceptionalities only when necessary. The consultant for this study provided ongoing coaching when she was at the camp sites and highlighted its importance in changing camp counsellors' practices. Depending on the age level and experience of the involved camp counsellors, this ongoing coaching aspect of program implementation can be challenging.

Future research will focus on examining the effect on social skills during similar and/or structured activities, gathering formalized parental feedback, investigating effects on individuals with varied disabilities, and looking at issues related to adult proximity. 
Future plans for Camps on TRACKS implementation include program continuation as a collaborative approach for inclusion and social skills development, local hiring of a program coordinator, and revisions to provided resources. Camps on TRACKS will also be extended to a residential camp setting: Since children at residential camp tend to spend more time together, it is likely that the positive results of using TRACKS strategies will continue or strengthen.

Overall, implementing Camps on TRACKS and peer-mediated approaches in the camp environment has many potential benefits that have been highlighted in this study and need to be investigated further. Regardless of whether the program is a day or residential setting, camp staff implementing Camps on TRACKS may experience a reduced need for one-on-one support. Once peers become familiar with the TRACKS strategies, they often begin using strategies independently, without further prompting. Finally, as peers become comfortable interacting with children who have social challenges, relationships begin, grow, and thrive among diverse children in inclusive camp settings.

\section{References}

Bellini, S. (2006). Building social relationships: A systemic approach to teaching social interaction skills to children and adolescents with autism spectrum disorders and other social difficulties. Shawnee Mission, KS: Autism Asperger Publishing Co.

Bellini, S., \& Hopf, A. (2007). The development of the Autism Social Skills Profile: A preliminary analysis of psychometric properties. Focus on Autism and Other Developmental Disabilities, 22(2), 80-87.

Bene, K., Banda, D. R., \& Brown, D. (2014). A meta-analysis of peer-mediated instructional arrangements and autism. Review Journal of Autism and Developmental Disorders, 1(2), 135-142. doi:10.1007/s40489-014-0014-9

Best Start Expert Panel on Early Learning. (2007). Early learning for every child today. Toronto, ON: Queen's Printer.

Brookman, L., Boettcher, M., Klein, E., Openden, D., Koegal, R., \& Koegal, L. (2003). Facilitating social interactions in a community summer camp setting for children with autism. Journal of Positive Behavior Interventions, 5, 249-252.

Corbett, B. A., Swain, D. M., Coke, C., Simon, D., Newsom, C., Houchins-Juarez, N., ... Song, Y. (2014). Improvement in social deficits in autism spectrum disorders using a theatre-based, peer-mediated intervention. Autism Research, 7(1), 4-16.

English, K., Shafer, K., Goldstein, H., \& Kaczmarek, L. (1997). Interaction among preschoolers with and without disabilities: Effects of across-the-day peer intervention. Journal of Speech and Hearing Research, 40, 33-48.

Gast, D. L. (2010). Single participant research methodology in behavioral sciences. New York, NY: Routledge.

Giangreco, M. F., Edelman, S. W., Luiselli, T. E., \& MacFarland, S. Z. (1997). Helping or hovering? Effects of instructional assistant proximity on students with disabilities. Exceptional Children, 64(1), 7-18.

Hall, C., Quinlan, L., Machado, M., Maich, K., \& Faragher, K. (2011). Camps on TRACKS. London, ON: City of London, Fanshawe College \& Thames Valley Children's Centre. 
Isaac, S., \& Michael, W.B. (1997). Handbook in research and evaluation (3rd ed.). San Diego, CA: EdITS Publications.

John, A. M., \& Gretchen, B. J. (1999). Logic models: A tool for telling your programs performance story. Evaluation and Program Planning, 22, 65-72. doi:10.1016/S0149-7189(98)00042-1

Kaboski, J. R., Diehl, J. J., Beriont, J., Crowell, C. R., Villano, M., Wier, K., \& Tang, K. (2014). Brief report: A pilot summer robotics camp to reduce social anxiety and improve social/vocational skills in adolescents with ASD. Journal of Autism and Developmental Disorders, 1-8. doi:10.1007/s10803-014-2153-3

Kamps, D., Mason, R., Thiemann-Bourque, K., Feldmiller, S., Turcotte, A., \& Miller, T. (2014). The use of peer networks to increase communicative acts of students with autism spectrum disorders. Focus on Autism and Other Developmental Disabilities, 29(4), 230-245. doi:10.1177/1088357614539832

Kashinath, S. P. (2012). Meta-analysis finds that peer-mediated and video-modeling social skills interventions are effective for children with autism, but caution is urged in interpreting the results. Evidence-Based Communication Assessment \& Intervention, 6(2), 58-62. doi:10.1080/17489539.2012.724201

Kazdin, A. E. (1978). Statistical analysis procedures for single-case experimental designs. In M. Hersen \& D. H. Barlow (Eds.), Single case experimental designs: Strategies for studying change (pp. 265-316). New York, NY: Pergamon Press.

Klavina, A. (2011). Using peer-mediated instructions for students with severe and multiple disabilities in inclusive physical education: A multiple case study. European Journal of Adapted Physical Activity, 1(2), 7-19.

Laushey, K. M., \& Heflin, L. J. (2000). Enhancing social skills of kindergarten children with autism through the training of multiple peers as tutors. Journal of Autism and Developmental Disorders, 30, 183-193.

Mason, R., Kamps, D., Turcotte, A., Cox, S., Feldmiller, S., \& Miller, T. (2014). Peer mediation to increase communication and interaction at recess for students with autism spectrum disorders. Research in Autism Spectrum Disorders, 8(3), 334-344. doi:10.1016/j.rasd.2013.12.014

McConnell, S. R. (2002). Interventions to facilitate social interaction for young children with autism: Review of available research and recommendations for educational intervention and future research. Journal of Autism and Developmental Disorders, 32(5), 351-372.

McFadden, B., Kamps, D., \& Heitzman-Powell, L. (2014). Social communication effects of peermediated recess intervention for children with autism. Research in Autism Spectrum Disorders, 8(12), 1699-1712. doi:10.1016/j.rasd.2014.08.015

Myles, B. S., Simpson, R. L., Ormsbee, C. K., \& Erickson, C. (1993). Integrating preschool children with autism with their normally developing peers: Research findings and best practice recommendations. Focus on Autistic Behavior, 8 (5), 1-18.

Parker, R., Vannest, K., \& Brown, L. (2009). The improvement rate difference for single-case research. Exceptional Children, 75(2), 135-150.

Schleien, S. J., Mustonen, T., \& Rynders, J. E. (1995). Participation of children with autism and nondisabled peers in a cooperatively structured community art program. Journal of Autism and Developmental Disorders, 25(4), 397-413.

Spencer-Cavaliere, N., \& Watkinson, E. J. (2010). Inclusion understood for the perspectives of children with disability. Applied Physical Activity Quarterly, 27, 275-293. 
Sperry, L., Neitzel, J., \& Engelhardt-Wells, K. (2010). Peer-mediated instruction and intervention strategies for students with autism spectrum disorders. Preventing School Failure, 54(4), 256-264.

Thiemann, K. (2006, April). Comprehensive social communication interventions for elementary students with ASD. Paper presented at ASD-School Support Program 2nd Annual Conference, Niagara Falls, ON.

Thiemann, K. S., \& Goldstein, H. (2004). Effects of peer training and written text cueing on social communication of school-age children with pervasive developmental disorder. Journal of Speech, Language, and Hearing Research, 47, 126-144. doi:10.1044/1092-4388(2004/012)

Utley, C. A., \& Mortweet, S. L. (1997). Peer-mediated instruction and interventions. Focus on Exceptional Children, 29(5), 1-23.

Wong, C., Odom, S. L., Hume, K. Cox, A. W., Fettig, A., Kucharczyk, S., ... Schultz, T. R. (2014). Evidence-based practices for children, youth, and young adults with autism spectrum disorder. Chapel Hill, NC: The University of North Carolina, Frank Porter Graham Child Development Institute, Autism Evidence-Based Practice Review Group. Retrieved from http://autismpdc.fpg.unc.edu/sites/autismpdc.fpg.unc.edu/files/2014-EBP-Report.pdf

Zhang, J., \& Wheeler, J. J. (2011). A meta-analysis of peer-mediated interventions for young children with autism spectrum disorders. Education and Training in Autism and Developmental Disabilities, 46(1), 62-77.

\section{Authors' Note}

Correspondence concerning this article should be addressed to Dr. Kimberly Maich, Department of Teacher Education, Brock University, 500 Glenridge Ave., St. Catharines, ON, L2S 3A1, Canada.Email: kmaich@brocku.ca 